\title{
Molecular cloning and characterization of the aroD gene encoding 3-dehydroquinase from Salmonella typhi
}

\author{
Spiros Servos, ${ }^{1,4}$ Steve Chatfield,${ }^{1}$ David Hone,, 3 Myron Levine, ${ }^{2}$ George Dimitriadis, ${ }^{4}$ \\ Derek Pickard, ${ }^{1}$ Gordon Dougan, ${ }^{1}$ NeIl Fairweather ${ }^{1}$ and Ian Charles ${ }^{1 *}$ \\ ${ }^{1}$ Department of Molecular Biology, Wellcome Biotech, Langley Park, South Eden Park Road, Beckenham, \\ Kent BR3 3BS, UK \\ ${ }^{2}$ Center for Vaccine Development, School of Medicine, and ${ }^{3}$ The Medical Biotechnology Center, University of Maryland, \\ 10 South Pine St, Baltimore, Maryland 21201, USA \\ ${ }^{4}$ University of Patras, Faculty of Sciences, Department of Biology, Division of Genetics, Cell and Development Biology, \\ Patras, Greece
}

(Received 3 July 1990; accepted 19 September 1990)

\begin{abstract}
The aroD gene from Salmonella typhi, encoding 5-dehydroquinate hydrolyase (3-dehydroquinase), has been cloned into Escherichia coli and the DNA sequence determined. The aroD gene was isolated from a cosmid gene bank by complementation of an $S$. typhimurium aroD mutant. Analysis of the DNA sequence revealed the presence of an open reading frame capable of encoding a protein of 252 amino acids with a calculated $M_{r}$ of 27706 . Comparison of the deduced $S$. typhi 3-dehydroquinase protein sequence with that elucidated for $E$. coli revealed $69 \%$ homology. Alignment of the $S$. typhi sequence and equivalent Aspergillus nidulans and Saccharomyces cerevisiae sequences showed that homology was lower, at $24 \%$, but still significant. Use of a minicell expression system demonstrated that a polyclonal antibody raised against $E$. coli 3-dehydroquinase cross-reacted with its $S$. typhi counterpart.
\end{abstract}

\section{Introduction}

The only biosynthetic route for the synthesis of aromatic compounds possessed by micro-organisms is the shikimate pathway, leading to the synthesis of chorismic acid, a central precursor for other aromatic compounds (Giles, 1978; Pittard, 1987). The products of the pathway include the aromatic amino acids $p$-aminobenzoic acid and 2,3-dihydroxybenzoate. The enzyme 3-dehydroquinase catalyses step three of the prechorismate part of the pathway and in bacteria is encoded by the gene aroD. In Escherichia coli, DNA sequence analysis of aroD has revealed the presence of a monocistronic gene capable of encoding a protein of 240 amino acid residues with a calculated $M_{\mathrm{r}}$ of 26377 (Duncan et al., 1986). By contrast, the plant enzyme consists of 3-dehydroquinase linked with shikimate dehydrogenase as a bifunctional polypeptide (Polley, 1978). The 3-dehydroquinase activity found in Aspergillus nidulans (Kinghorn \& Hawkins, 1982; Charles et al., 1986; Hawkins, 1987), Neurospora crassa (Lumsden \& Coggins, 1977; Catcheside et al., 1985) and

The nucleotide sequence data reported in this paper have been submitted to EMBL and assigned the accession number X54546.
Saccharomyces cerevisiae (Duncan et al., 1987) has been identified as part of a pentafunctional polypeptide. In each case, the large polypeptide carries the enzyme activities associated with steps two to six of the prechorismate part of the pathway. In addition to these biosynthetic activities an inducible catabolic dehydroquinase involved in the quinic acid catabolic pathway has been characterized from $A$. nidulans (Hawkins et al., 1982) and $N$. crassa (Giles et al., 1985). In $A$. nidulans the quinate-inducible 3-dehydroquinase is the product of the $Q u \mathrm{TE}$ gene and has an $M_{\mathrm{r}}$ of 16505 . A similarly sized protein from $N$. crassa, the product of the $Q A 2$ locus, has considerable homology to the $Q u T E$ gene product ( $\mathrm{Da}$ Silva et al., 1986). Neither of these two catabolic dehydroquinase genes or their deduced protein sequences shows any significant homology with their biosynthetic counterparts.

In our laboratories, interest in the shikimate pathway has come from the observation that pathogenic organisms with genetic lesions in genes encoding enzymes involved in the prechorismate pathway grow poorly in vivo (Dougan et al., 1987; Levine et al., 1987; O'Callaghan et al., 1988) and are of potential use as live vaccines (Bacon et al., 1951; Hoiseth \& Stocker, 1981). 
Shikimate pathway enzymes are also absent from mammalian species, and consequently have been the target for chemotherapeutic agents and broad-range herbicides (Kishore \& Shah, 1988). As part of our research programme to generate aromatic amino acid dependent mutants of pathogenic organisms in order to evaluate their utility as live-attenuated vaccines (Dougan et al., 1987), we have cloned, sequenced and characterized a number of aro genes from different microorganisms (Charles et al., 1985, 1986, 1990; Maskell et al., 1988). In this paper we report the cloning and characterization of the aroD gene from Salmonella typhi, and demonstrate homology between its deduced protein sequence and the protein sequences of other biosynthetic 3-dehydroquinase enzymes.

\section{Methods}

Strains, bacteriophage and plasmids. E. coli $\mathrm{K} 12$ strain TG1 $[\Delta($ lac-

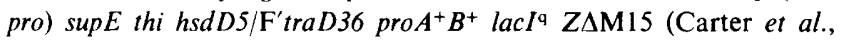
1985)] was the kind gift of Dr T. Gibson, Laboratory of Molecular Biology, Cambridge, UK. E. coli SK 2881 (F- aroD6 leuC hsdR4 recAI) has been described by Kushner (1978). S. typhimurium strain S68 [his6165 ilv-452 met A22 metE551 trpB2 galE496 xyl-404 rpsL20 flaA6 hsdL6 $h s d S A 29 \operatorname{lam} B(E$. coli) $z j a:: \operatorname{Tn} 105$ ] harbours the $\operatorname{lam} B$ gene from $E$. coli integrated into the chromosome and is susceptible to bacteriophage $\lambda$ infection when grown on $0.2 \%$ maltose ; it was the kind gift of Professor B. Stocker, Department of Medical Microbiology, Stanford University, California, USA. S. typhimurium CU038 (aroD), S. typhi Ty2 (aroA : $: \operatorname{Tn} 10$ ) and bacteriophage $\mathrm{P} 22$ have been described previously (Dougan et al., 1987; Miller et al., 1989).

Cosmid pHC79 (Hohn \& Collins, 1980) was obtained from Amersham. Transposon Rts1 : $\operatorname{Tn} 1725$ has been described (Ubben \& Schmitt, 1986). M13mp18 and M13mp19 (Messing \& Vieira, 1982) were supplied by Pharmacia. Minicells were prepared using $E$. coli strain DS410 (Dougan \& Sherratt, 1977).

Media and reagents. S. typhimurium, $S$. typhi and E. coli were grown in Luria broth (LB) or LB solidified with $1.6 \%(\mathrm{w} / \mathrm{v})$ agar. For testing auxotrophic requirements, minimal medium (MM) or MM with $2 \%$ (w/v) Noble agar (Difco) was used (Miller, 1972). Restriction endonucleases were supplied by BRL Gibco and Pharmacia. The T7 and Klenow DNA sequencing kits were supplied by Pharmacia and Cambridge Bioscience. T4 DNA ligase was from Boehringer. $\left[{ }^{35}\right.$ S $]$ dATP was from Amersham.

DNA isolation and Tn1725 mutagenesis. Plasmid DNA was isolated by the alkaline-SDS lysis method (Maniatis et al., 1982). DNA restriction endonuclease fragments were isolated by the method of Tautz \& Renz (1983). Chromosomal DNA was prepared by the method of Hull et al. (1981) as modified by Maskell et al. (1988). Tn1725 mutagenesis and mapping was carried out by the method of Ubben \& Schmitt (1986)

Construction of an S. typhi chromosomal gene bank in pHC79. Chromosomal DNA from $S$. typhi aroA:: $\operatorname{Tn} 10$ was partially digested with Sau $3 \mathrm{~A}$ and fragments in the size range $23-40 \mathrm{~kb}$ were size-selected as described previously (Maniatis et al., 1982; Morrissey \& Dougan, 1986) and ligated into BamHI-digested pHC79 (Hohn \& Collins, 1980). Cosmids were packaged in vitro with a kit supplied by Amersham using conditions recommended by the manufacturer, and phage plated out as described previously (Miller et al., 1989). A high-titre stock of

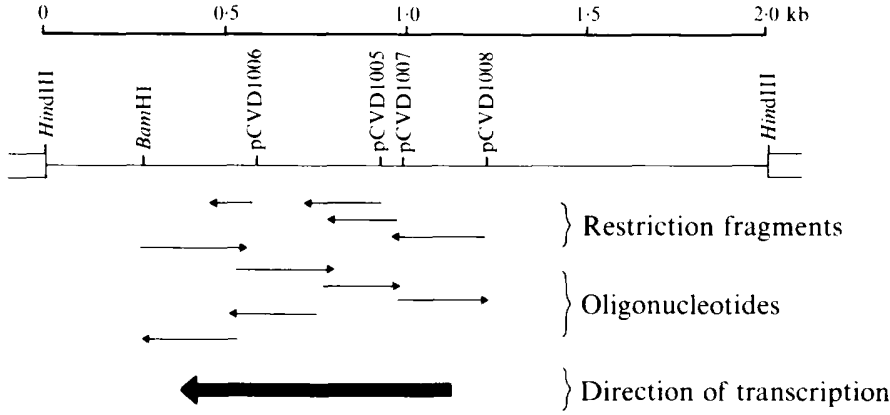

Fig. 1. Sequencing strategy for the $S$. typhi aroD gene. The sites marked pCVD1005, pCVD1006, pCVD1007 and pCVD1008 identify the position of four plasmids harbouring $\operatorname{Tn} 1725$ insertions that were used to generate subclones for DNA sequencing.

packaged recombinant phage was mixed with $S$. typhimurium AS68 at an m.o.i. of $0 \cdot 1$, and recombinants selected on LB plates containing ampicillin at a concentration of $50 \mu \mathrm{g} \mathrm{ml}^{-1}$. Several thousand recombinants were pooled, and a P22 stock was generated by standard methods (Davis et al., 1980). This P22 bank was subsequently used to complement $S$. typhimurium strain CU038 (aroD).

Minicells experiments and Western blotting. Minicell experiments and SDS-PAGE were carried out as described by Dougan \& Sherrat (1977). The procedure used for Western blotting was as described by Towbin $e t$ al. (1979).

DNA sequencing. Single-stranded DNA templates were sequenced using Klenow (Sanger et al., 1977) or T7 DNA polymerase (Tabor \& Richardson, 1987), using kits supplied by Pharmacia and Cambridge Bioscience. Labelled fragments were separated on buffer gradient polyacrylamide/urea gels (Biggin et al., 1983). DNA sequencing was initiated from sites within the $S$. typhi aroD gene by cloning EcoRI fragments from four independent aro $D$-associated $\mathrm{Tn} 1725$ transposon insertions (Ubben \& Schmitt, 1986). Gaps in the sequence were filled in using synthetic oligonucleotides as specific primers (Charles et al., 1985, 1986; Strauss et al., 1986).

Oligonucleotides. Oligonucleotide primers were synthesized on a SAMI oligonucleotide synthesizer (Biolabs, UK).

\section{Results and Discussion}

\section{Cloning and mapping of the S. typhi gene for aroD} in E. coli

A cosmid gene bank generated in pHC79 was used to complement an aroD lesion in S. typhimurium CU038. Transformants were selected on MM containing ampicillin at a concentration of $50 \mu \mathrm{g} \mathrm{ml}^{-1}$, but lacking aromatic compounds. Colonies were visible after $48 \mathrm{~h}$ incubation at $37^{\circ} \mathrm{C}$. Of the initial six transformants that were picked on their ability to complement an aroD lesion, a single recombinant cosmid, pWBTYD1, that demonstrated recomplementation was selected for further analysis by transposon mapping, DNA sequencing and minicell-directed protein synthesis. 


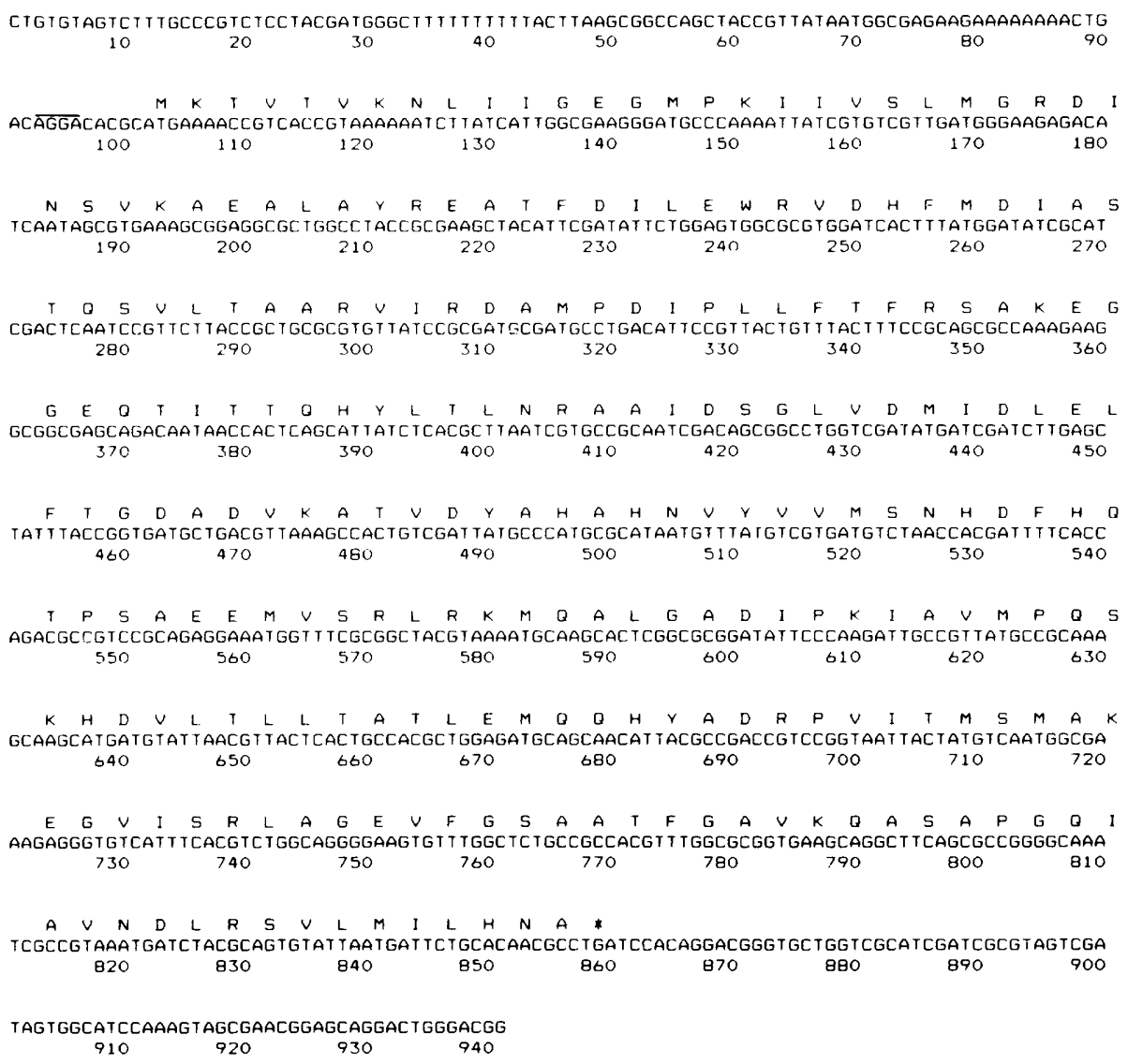

Fig. 2. The nucleotide and derived amino acid sequence of the aroD gene from $S$. typhi. The overlined sequence at positions $93-96$ indicates a possible ribosome-binding site. The open reading frame for $a r o D$ comprises 252 amino acids capable of encoding a protein of $M_{\mathrm{r}} 27706$.

\section{Subcloning and transposon mutagenesis of S. typhi aroD}

Initial restriction endonuclease mapping of cosmid pWBTYD1 demonstrated that it carried an insert of $22 \mathrm{~kb}$. In order to characterize a smaller fragment that still complemented aroD, HindIII, EcoRI and $B g l \mathrm{II}$ fragments were subcloned into pUC18 and the ligation mixtures used to transform $E$. coli SK2881. Analysis of aroD-complementing recombinants by plasmid minipreps (Maniatis et al., 1982) showed that one recombinant, pCVDl001, carried an $8.2 \mathrm{~kb} \mathrm{BgllI}$ fragment. This plasmid was used as a substrate for Tn1725 mapping as described previously (Ubben \& Schmitt, 1986). Four pCVD1001::Tn 1725 isolates were identified, three of which no longer complemented the $E$. coli aro $D$ mutant SK2881, and were used in the subsequent DNA sequencing strategy (Fig. 1).

\section{Nucleotide sequence of $S$. typhi aroD}

A $2 \mathrm{~kb}$ HindIII fragment, identified by transposon mapping of the $8.2 \mathrm{~kb} \mathrm{Bg} / \mathrm{II}$ fragment as covering the region corresponding to the $S$. typhi aroD gene, was cloned into M13mp18 in both orientations. These M13 templates were used as the substrates for the synthetic oligonucleotide primers. Tn 1725 mutagenesis generated four plasmids, pCVD1005, pCVD1006, pCVD1007 and pCVD1008, the first three of which no longer complemented the E. coli aroD strain SK2881, presumably because of gene disruption. As a consequence of these transposon insertions, additional EcoRI sites were introduced into the gene for $\operatorname{aro} D$ and these new sites were used to conveniently clone aro $D$-associated fragments into M13mp18 and M13mp19 for DNA sequencing (see Fig. 1). Gaps in the sequence were filled in using synthetic oligonucleotides as specific sequencing primers. Analysis of the DNA sequence (Fig. 2) reveals the presence of an open reading frame capable of encoding a protein of 252 amino acids with a calculated $M_{\mathrm{r}}$ of 27706.

\section{Putative regulatory elements for the $S$. typhi aroD gene}

Examination of the DNA sequence (Fig. 2) reveals the presence of two regions with a good fit to the consensus 


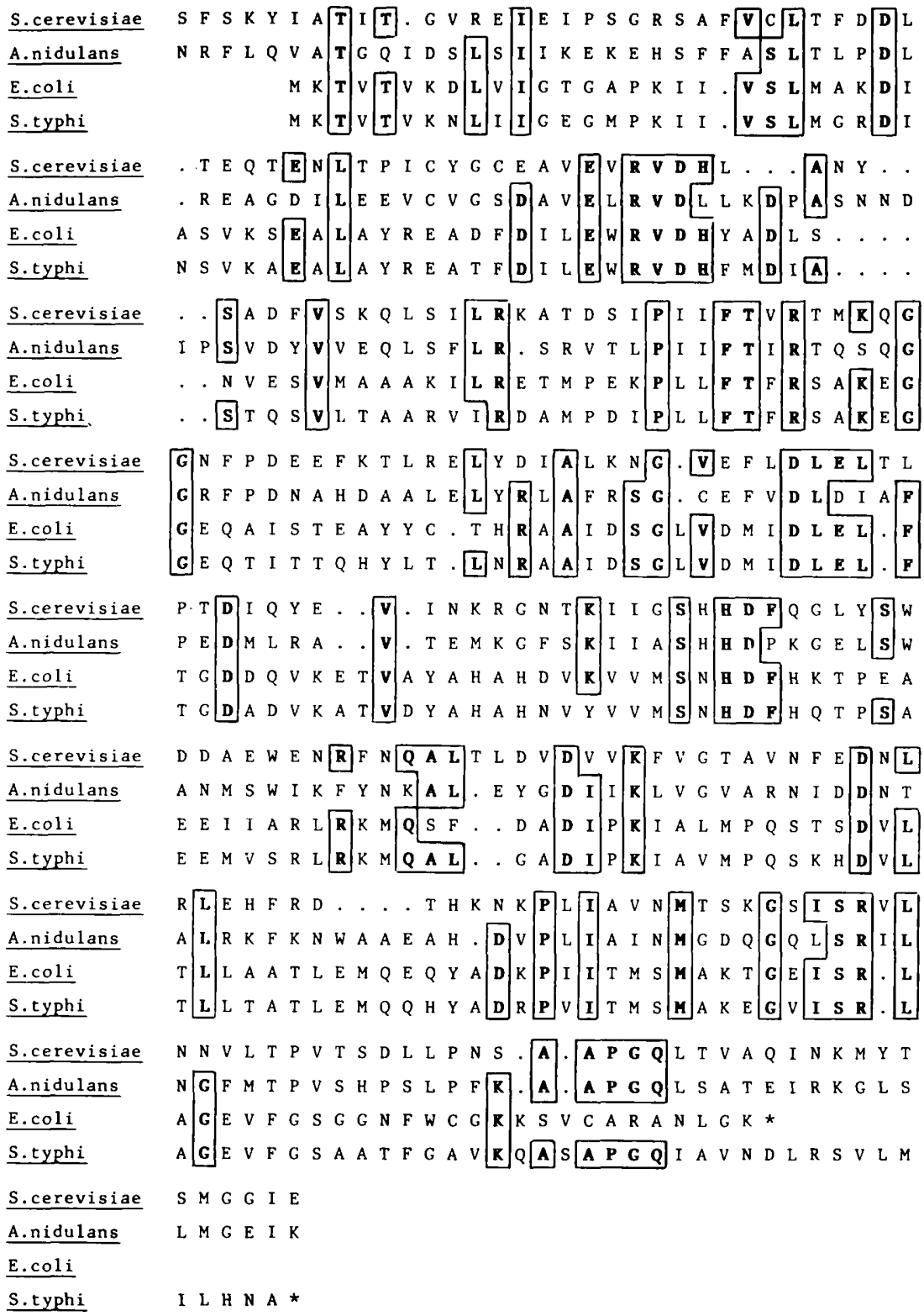

Fig. 3. Amino acid homologies between the $S$. typhi aroD gene product and other published 3-dehydroquinase sequences. Sequences that are common to three or more of the species are boxed. Dots refer to regions of variable length that are introduced in the sequences to produce a best fit for regions of homology.

-10 and -35 promoter elements (Rosenberg \& Court, 1979). The sequence 5'-TATAAT-3' from nucleotides 65 to 70 is an exact match with the -10 consensus sequence, while the sequence 5'-TTTACT-3' from nucleotides 41 to 46 with a spacing of 18 bp has a $4 / 6$ match with the consensus -35 region.

Comparison of the DNA sequence flanking the structural gene for aroD from $S$. typhi with the $E$. coli aro $D$ flanking regions shows little homology, although both sequences have a candidate AGG ribosomebinding site (Shine \& Dalgarno, 1974). In the E. coli aroD sequence an inverted repeat has been noted 48 bp after the end of the structural gene but this feature is apparently absent from the $S$. typhi aroD sequence.

\section{Comparison of the $S$. typhi and E. coli aroD sequences}

Comparison of the sequences shows a high degree of homology, $69.6 \%$ at the protein level, and $68.7 \%$ when DNA sequences were aligned. Many of the observed protein changes are, however, conservative substitutions. Interestingly, the sequence from $S$. typhi comprises 


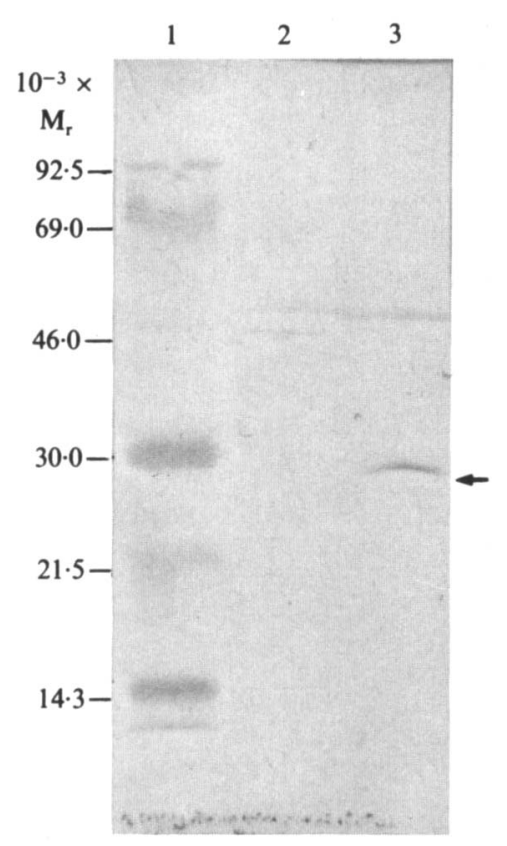

Fig. 4. Western blot showing minicell-directed proteins separated by SDS-PAGE transferred to nitrocellulose and reacted with anti-E. coli 3-dehydroquinase $(a r o D)$ antibody. Track 1, $M_{\mathrm{r}}$ markers; track 2, cosmid pHC79 (negative control); track 3 , cosmid pWBTYD1 (expressing 3-dehydroquinase). An arrow indicates the position of a $28 \mathrm{kDa}$ band in track 3 that corresponds to 3-dehydroquinase. Fainter higher- $M_{\mathrm{r}}$ bands seen in tracks 2 and 3 are cross-reacting proteins that are incidental to 3-dehydroquinase.

252 amino acid residues, while the sequence from $E$. coli has 240 residues. This sequence difference appears to be the consequence of an error in the published $E$. coli sequence for aro $D$. Resequencing the $E$. coli gene indicates that it also comprises 252 amino acid residues (J. Coggins \& L. Graham, personal communication).

Comparison of the codon usage table of $S$. typhi aroD with that derived for another gene encoding a protein involved in aromatic amino acid biosynthesis from $S$. typhi, the aroC gene (Charles et al., 1990), shows a high degree of similarity in the choice of which codons are most frequently used. The pattern is consistent for those genes that are poorly expressed in E. coli (Grantham et al., 1981). There are some minor differences in codon preference, e.g. in the $S$. typhi aroC gene the most popular codon for alanine is GCG, while in the $S$. typhi aroD it is GCC.

\section{Alignment of four biosynthetic dehydroquinase enzymes}

Homology between four biosynthetic dehydroquinase enzymes is displayed in Fig. 3. The figure was obtained by comparing the deduced $S$. typhi 3-dehydroquinase protein sequence individually with those for $E$. coli,
Aspergillus nidulans and Saccharomyces cerevisiae using the program ALIGN (Staden, 1982). The four sequences were then compiled together by eye. Boxes have been drawn around sequences that are conserved in three or more of the proteins.

\section{Minicell-directed polypeptide expression from an aroD recombinant}

Cosmid pWBTYD1 encoding the $S$. typhi aroD gene was transferred to the minicell-producing strain DS410. Plasmid-harbouring minicells were purified, labelled with $\left[{ }^{35}\right.$ S $]$ methionine and analysed using SDS-PAGE followed by Western blotting. Proteins were transferred to nitrocellulose, and reacted with antibody raised against $E$. coli 3-dehydroquinase (kindly supplied by $\mathbf{J}$. Coggins, University of Glasgow, UK). The results are shown in Fig. 4. The aroD-complementing cosmid (track 3) directs the expression of a protein of $M_{\mathrm{r}}$ approximately 28000 (marked with an arrow), which is in good agreement with the value of 27706 deduced from the DNA sequence. This polypeptide is absent from the control (track 2) sample prepared from minicells harbouring pHC79 vector. Cross-reacting bands of lower mobility, present in both the negative control (track 2) and track 1, are incidental to 3-dehydroquinase expression.

We thank Professor J. Coggins for supplying antibody to E. coli 3dehydroquinase, and L. Graham for supplying us with information about the revised $E$. coli aroD sequence prior to publication. We also thank Hugh Spence for making oligonucleotides, Steve Nicholls for advice on computing and Tina Silva for typing the manuscript.

\section{References}

Bacon, G. A., Burrows, T. W. \& Yates, M. (1951). The effects of biochemical mutation on the virulence of Bacterium typhosum: the loss of virulence of certain mutants. British Journal of Experimental Pathology 32, 85-96.

Biggin, M. D., Gibson, T. G. \& Hong, G. F. (1983). Buffer gradient gels and ${ }^{35} \mathrm{~S}$ label as an aid to rapid DNA sequence determination. Proceedings of the National Academy of Sciences of the United States of America 80, 3963-3965.

Carter, P., Bedouelle, H. \& Winter, G. (1985). Improved oligonucleotide site directed mutagenesis using M13 vectors. Nucleic Acids Research 13, 4431-4443.

CAtcheside, D. E. A., Storer, P. J. \& KLein, B. (1985). Cloning of the ARO cluster gene of Neurospora crassa and its expression in Escherichia coli. Molecular and General Genetics 199, 446-451.

Charles, I. G., Keyte, J. W., Brammar, W. J. \& Hawkins, A. R. (1985). Nucleotide sequence encoding the biosynthetic dehydroquinase function of the penta-functional $A R O M$ locus of Aspergillus nidulans. Nucleic Acids Research 13, 8119-8128.

Charles, I. G., Keyte, J. W., Brammar, W. J., Smith, M. \& Hawkins, A. R. (1986). The isolation and nucleotide sequence of the complex AROM locus of Aspergillus nidulans. Nucleic Acids Research 14, 22012213. 
Charles, I. G., Lamb, H. K., Pickard, D., Dougan, G. \& Hawkins, A. R. (1990). Isolation, characterisation and nucleotide sequences of the aroC genes encoding chorismate synthase from Salmonella typhi and Escherichia coli. Journal of General Microbiology 136, 353-358.

Da Silva, A J. F., Whittington, H., Clements, J., Roberts, C. \& HAWKINS, A. R. (1986). Sequence analysis and transformation by the catabolic 3-dehydroquinase (QUTE) gene from Aspergillus nidulans. Biochemical Journal 240, 481-488.

DAvis, R. W., BotsteIN, D. \& Roth, J. R. (1980). Advanced Bacterial Genetics. A Manual for Genetic Engineering. Cold Spring Harbor, NY: Cold Spring Harbor Laboratory.

Dougan, G. \& SherRatT, D. J. (1977). Tn $a$ as a probe for the structure and function of ColE1. Molecular and General Genetics 151, 151-160.

Dougan, G., Maskell, D., Pickard, D. \& Hormaeche, C. (1987). Isolation of stable aroA mutants of Salmonella typhi Ty2: properties and preliminary characterisation in mice. Molecular and General Genetics 207, 402-405.

Duncan, K., Chaudhuri, S., Campbell, M. S. \& Coggins, J. R. (1986). The over-expression and complete amino acid sequence of Escherichia coli 3-dehydroquinase. Biochemical Journal 238, 475-483.

DunCan, K., Edwards, R. M. \& CogGins, J. R. (1987). The pentafunctional $A R O M$ enzyme of Saccharomyces cerevisiae is a mosaic of monofunctional domains. Biochemical Journal 246, 375386.

GiLes, N. H. (1978). The organisation, function and evolution of gene clusters in eukaryotes. American Naturalist 112, 641-657.

Giles, N. H., Case, M. F., Baum, J., Geever, R., Huiet, L., Patel, V., TYLER, B. (1985). Gene organization and regulation in the QA (quinic acid) gene cluster of Neurospora crassa. Microbiology Reviews 49, 338-358.

Grantham, R., Gautier, C., Gouy, M., Jacobzone, M. \& Mercier, R. (1981). Codon catalogue usage is a genome strategy modulated for gene expressivity. Nucleic Acids Research 9, 43-47.

Hawkins, A. R. (1987). The complex $A R O M$, locus of Aspergillus nidulans: evidence for multigene fusions and convergent evolution. Current Genetics 11, 491-498.

Hawkins, A. R., Giles, N. H. \& KinghorN, J. R. (1982). Genetical and biochemical aspects of quinate breakdown in the filamentous fungus Aspergillus nidulans. Biochemical Genetics 20, 271-286.

HoHN, B. \& Collins, J. (1980). A small cosmid for efficient cloning of large DNA fragments. Gene 11, 291-298.

HoISETH, S. K. \& STOCKER, B. A. D. (1981). Aromatic-dependent Salmonella typhimurium are non-virulent and are effective live vaccines. Nature, London 291, 238-239.

Hull, R. A., Gill, R. E., Hsu, P., Minshew, B. H. \& Falkow, S. (1981). Construction and expression of recombinant plasmids encoding Type 1 of D-mannose-resistant pili from a urinary tract infection Escherichia coli isolate. Infection and Immunity 33, 933-938.

KINGHORN, J. R. \& HAwKINS, A. R. (1982). Cloning and expression in Escherichia coli $\mathrm{K} 12$ of the biosynthetic dehydroquinase function of the $A R O M$ cluster gene from the eukaryote Aspergillus nidulans. Molecular and General Genetics 186, 145-152.

Kishore, G. M. \& SHAH, D. M. (1988). Amino acid biosynthesis inhibitors as herbicides. Annual Review of Biochemistry 57, 627-663.

KUSHNER, S. R. (1978). An improved method for transformation of Escherichia coli with ColE I derived plasmids. In Genetic Engineering, pp. 17-23. Edited by H. W. Boyer \& S. Nicosia. Amsterdam: Elsevier/North-Holland Biomedical Press.

Levine, M. M., Herrington, D., Murphy, J. R., Morris, J. G., Losonsky, G., Tall, B., Linberg, A. A., Svenson, S., Baqar, S., Frances-Edwards, M. \& Stocker, B. (1987). Safety, infectivity, immunogenicity, and in vivo stability of two attenuated auxotrophic mutant strains of Salmonella typhi 541Ty and 543Ty, as live oral vaccines in humans. Journal of Clinical Investigation 79, 888-902.

Lumsden, J. \& Coggins, J. R. (1977). The subunit structure of the
AROM multienzyme complex of Neurospora crassa. A possible pentafunctional polypeptide chain. Biochemical Journal 161, 599607.

Maniatis, R., Fritsch, E. F. \& Sambrook, J. (1982). Molecular Cloning : a Laboratory Manual. Cold Spring Harbor, New York : Cold Spring Harbor Laboratory.

Maskell, D. J., Morrissey, P. \& Dougan, G. (1988). The cloning and nucleotide sequence of the aroA gene of Bordetella pertussis. Journal of Bacteriology 170, 2467-2471.

Messing, J. \& VieIRA, J. (1982). A new pair of M13 vectors for selecting either DNA strand of double digested restriction fragments. Gene 19 , 269-276.

MiLLER, J. M. (1972). Experiments in Molecular Genetics. Cold Spring Harbor, New York: Cold Spring Harbor Laboratory.

Miller, I. A., Chatfield, S., Dougan, G., DeSilva, L., Joysey, H. S. \& HoRMAeCHE, C. E. (1989). Bacteriophage P22 as a vehicle for transducing cosmid gene banks between smooth strains of Salmonella typhimurium: use in identifying a role for aro $D$ in attenuating virulent Salmonella strains. Molecular and General Genetics 215, 312316.

MoRrissey, P. \& Dougan, G. (1986). Cloning and characterisation of the Escherichia coli $987 \mathrm{P}$ adhesion fimbriae determinant. Gene $\mathbf{4 3}$, 79-84.

O'Callaghan, D., Maskell, D., Liew, F. Y., Easmon, C. S. \& Dougan, G. (1988). Characterisation of aromatic and purine dependent Salmonella typhimurium: attenuation, persistence and ability to induce protective immunity in BALB/c mice. Journal of Bacteriology 56, 419-423.

PitTaRd, A. J. (1987). Biosynthesis of the aromatic amino acids. In Escherichia coli and Salmonella typhimurium. Cellular and Molecular Biology. Edited by F. C. Neidhardt. Washington, DC: American Society for Microbiology.

Polley, L. D. (1978). Purification and characterization of 3dehydroquinate hydrolase and shikimate oxidoreductase, evidence for a bifunctional enzyme. Biochemica et Biophysica Acta 526, 259266.

ROSENBERG, M. \& COURT, M. (1979). Regulatory sequences involved in the promotion and termination of RNA transcription. Annual Review of Genetics 13, 319-353.

Sanger, F., Nicklen, S. \& Coulson, A. R. (1977). DNA sequencing with chain terminating inhibitors. Proceedings of the National Academy of Sciences of the United States of America 71, 5463-5467.

Shine, J. \& Dalgarno, L. (1974). The $3^{\prime}$ terminal sequence of Escherichia coli $16 \mathrm{~S}$ ribosomal RNA : complementarity to nonsense triplets and ribosome binding sites. Proceedings of the National Academy of Sciences of the United States of America 71, 1342-1346.

STADEN, R. (1982). An interactive graphics program for comparing and aligning nucleic acid and amino acid sequences. Nucleic Acids Research 10, 2951-2961.

Strauss, E. C., Kobori, J. A., Siu, G. \& Hood, L. E. (1986). Specificprimer-directed DNA sequencing. Analytical Biochemistry 154, 353360.

TABOR, S. \& RICHARDSON, C. C. (1987). DNA sequence analysis with a modified bacteriophage T7 polymerase. Proceedings of the National Academy of Sciences of the United States of America 84, 4767-4771.

TAUTZ, D. \& RENZ, M. (1983). An optimised freeze-squeeze method for the recovery of DNA fragments from agarose gels. Analytical Biochemistry 132, 14-19.

Towbin, H., Staehelin, T. \& GoRdon, J. (1979). Electrophoretic transfer of proteins from polyacrylamide gels to nitrocellulose sheets: procedure and some applications. Proceedings of the National Academy of Sciences of the United States of America 76, 4350-4354.

UbBeN, D. \& SChMITT, R. (1986). Tn 1721 derivatives for transposon mutagenesis, restriction mapping and nucleotide sequence analysis. Gene 41, 145-152. 